\title{
Arginine Vasopressin Levels during a Painful Stimulus in Infancy
}

\author{
CAROLYN B. WATERS, JOSEPH E. WEINBERG, ROSEMARY D. LEAKE, ${ }^{(9)}$ AND \\ DELBERT A. FISHER \\ Division of Perinatology, Department of Pediatrics, UCLA School of Medicine, Harbor-UCLA Medical Center, \\ Torrance, California, USA
}

\section{Summary}

Plasma arginine vasopressin concentrations were measured in eight healthy, full term male infants before and during circumcision. There was no change in mean ( \pm S.E.) plasma arginine vasopressin level from the baseline period $(2.1 \pm 0.5 \mu \mathrm{U} / \mathrm{ml})$ to $1-$ $\mathbf{2}$ min after application of a crushing clamp on the dorsal foreskin (1.8 $\pm 0.7 \mu \mathrm{U} / \mathrm{ml})$.

\section{Speculation}

Unlike adults, the healthy newborn appears to tolerate a painful stimulus without increased plasma arginine vasopressin.

Plasma arginine vasopressin (AVP) levels are elevated in response to hypovolemic and hyperosmolal stimuli in adults. In addition, inappropriate antidiuresis is a frequent postoperative occurrence in adults, perhaps secondary to pain (6). Kendler et al. showed increased plasma AVP concentrations in adults with chronic pain (3). There have been several reports showing prompt AVP release after skin incision in adult surgical cases (2-5). Hoppenstein found increased AVP concentrations by bioassay in infants as a response to surgery, with higher levels in older infants (2). However, there are no radioimmunoassay data relating AVP levels and pain in children.

The present study was conducted to explore the effect of pain on AVP secretion in the human infant; AVP levels were measured in infants during circumcision.

\section{MATERIALS AND METHODS}

AVP were measured in eight healthy full term males before and during circumcision. Infants undergoing circumcision were 2-3 day old, healthy, appropriate size for gestational age, full term males being circumcised at the parents' request. None experienced complications during the procedure. The infants were fasted for $3-5 \mathrm{~h}$ before study after which a baseline $2 \mathrm{ml}$ venous blood sample was drawn from a peripheral vein with the infant positioned on the circumcision board. A second blood sample was drawn in an identical fashion beginning 1-2 min after application of the crushing clamp to the dorsal foreskin. Elapsed time between samples was 5-7 min.

All aspects of this study were approved by the Harbor/UCLA Medical Center Human Subjects Committee; informed parental consent was obtained in each instance.

Blood samples were placed in iced tubes containing $10.5 \mathrm{mg}$ potassium EDTA and spun at $1300 \times g$ in a refrigerated centrifuge. Plasma was stored at $-20^{\circ} \mathrm{C}$ until quantification; plasma AVP was extracted and concentrations measured by a radioimmunoassay method developed in our laboratory and previously described (7).
Plasma AVP concentrations before and during circumcision were compared by a paired $t$ test.

\section{RESULTS}

Mean ( \pm S.E.) plasma AVP levels were $2.1 \pm 0.4 \mu \mathrm{U} / \mathrm{ml}$ at baseline and $1.8 \pm 0.7 \mu \mathrm{U} / \mathrm{ml} \mathrm{1-2} \mathrm{min} \mathrm{after} \mathrm{applying} \mathrm{the} \mathrm{crushing}$ clamp to the dorsal foreskin (N.S.). All infants were crying vigorously at the time of the second blood sample.

\section{DISCUSSION}

Painful stimuli are known to cause AVP secretion in adults (35), but there are few data measuring this response in infants. Using circumcision as the painful stimulus, we were unable to demonstrate a significant plasma AVP rise above baseline levels. Our baseline values, however, were somewhat higher than levels previously reported in newborns of similar age (1). This result is unlikely to be due to the pain of venipuncture, because we have shown in our laboratory that there is no significant difference between measurements in umbilical arterial (by catheter) and peripheral venous (by venipuncture) AVP levels obtained sequentially over $2 \min (n=6)$. Rather, these values presumably reflect the fasting (and thirsting) state of the newborn who had not yet fully established feedings. In addition, many of the previously reported A.VP values for infants older than $24 \mathrm{~h}$ of age were receiving intravenous fluids to maintain hydration (1).

There is no evidence from the present study that brief periods of pain produce an increase in AVP in the first wk of life.

\section{REFERENCES AND NOTES}

1. Hadeed, A. J., Leake, R. D., Weitzman, R. E., Fisher, D. A.: Possible mechanisms of high blood levels of vasopressin during the neonatal period. J. Pediatr., 94: 805 (1979).

2. Hoppenstein, J. M., Miltenberger, F. W., Moran, W. H., Jr.: The increase in blood levels of vasopressin in infants during birth and surgical procedures. Surg. Gynecol. Obstet., 127: 966 (1968).

3. Kendler, K. S., Weitzman, R. E., Fisher, D. A.: The effect of pain on plasma arginine vasopressin concentrations in man. Clin. Endocrinol., 8: 89 (1978).

4. Moran, W. H., Zimmerman, B.: Mechanisms of antidiuretic hormone (ADH) control of importance to the surgical patient. Surgery, 62: 639 (1967)

5. Simpson, P. J., Forsling, M. L.: The effect of halothane anaesthesia on plasma vasopressin during cardiopulmonary bypass. Clin. Endocrinol., 2: 33 (1977).

6. Sinnatamby, C., Edwards, C. R. W., Kitau, M., et al.: Antidiuretic hormone response to high and conservative fluid regimes in patients undergoing operation. Surg. Gynecol. Obstet., 139: 715 (1974).

7. Skowsky, W. R., Rosenbloom, A. A., Fisher, D. A.: Radioimmunoassay measurement of arginine vasopressin in serum: Development and application. J. Clin. Endocrinol. Metab., 38: 278 (1974)

8. Philbin, D. M., Wilson, N. E., Sokoloski, R. A.: Radioimmunoassay of antidiuretic hormone during morphine anaesthesia. Can. Anaesth. Soc. J., 23: 290 (1976)

9. Requests for reprints should be addressed to: Dr. Rosemary D. Leake, 1000 W. Carson St., Torrance, CA 90509.

10. Received for publication June 12, 1981.

11. Accepted for publication December 1, 1981. 